\title{
Problems and Countermeasures of Training Professional Masters of Clinical Medicine in the “Two-Track Integration” Mode
}

\author{
Haige Huang1*, Jihua Wei1*, Qiong Liang1, Xusen Huang², Chongchan Bao², Yan Jiang2, Bin Ge1,

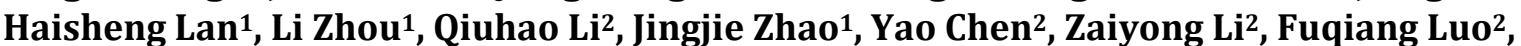 \\ Kangqi Xie ${ }^{2}$, Zechen Wang², Fangyin Liu², Qianli Tang², Lingzhang Meng#
}

${ }^{1}$ The Affiliated Hospital of Youjiang Medical University for Nationality, Baise City, China

${ }^{2}$ Youjiang Medical University for Nationalities, Baise City, China

Email: "lingzhang.meng@ymcn.edu.cn

How to cite this paper: Huang, H. G., Wei, J. H., Liang, Q., Huang, X. S., Bao, C. C., Jiang, Y., Ge, B., Lan, H. S., Zhou, L., Li, Q. H., Zhao, J. J., Chen, Y., Li, Z. Y., Luo, F. Q., Xie, K. Q., Wang, Z. C., Liu, F. Y., Tang, Q. L., \& Meng, L. Z. (2021). Problems and Countermeasures of Training Professional Masters of Clinical Medicine in the "TwoTrack Integration” Mode. Creative Education, 12, 486-493.

https://doi.org/10.4236/ce.2021.123034

Received: January 27, 2021

Accepted: March 2, 2021

Published: March 5, 2021

Copyright $\odot 2021$ by author(s) and Scientific Research Publishing Inc. This work is licensed under the Creative Commons Attribution International License (CC BY 4.0).

http://creativecommons.org/licenses/by/4.0/

\begin{abstract}
A discussion is conducted on the problems of ideological and political education, rotation learning in departments, clinical and scientific research capabilities, paper writing, and improvement of the quality of papers encountered by professional master of clinical medicine in the "two-track integration" mode during the standardized training of resident doctors. On that basis, several methods are proposed in the present study (e.g., stressing ideological education for professional masters, coordinating learn of professional skills, enhancing paper writing ability and scientific research ability, organizing a professional team of tutors). On that basis, this study summarizes the problems and challenges exposed in training professional medical students, especially under "two-track integration" mode, seeks to propose a novel idea to serve better for the "two-track integration" educational mode, including provide solutions to help students establish learning goals, to enhance their writing ability, to narrow the bridge between teachers and students, etc. All of which, aims to optimize the training of professional masters of clinical medicine, and give some feasible suggestions for subsequent research. Hopefully, the suggestions and proposal in this study would draw attention and serve better to increase the education quality on professional medical students.
\end{abstract}

\section{Keywords}

"Two-Track Integration" Mode, Professional Masters of Clinical Medicine, Standardized Training for Residents

*These authors contributed equally to this study; ${ }^{\sharp}$ Corresponding author. 


\section{Requirements for "Professional Masters" in “Two-Track Integration" Mode}

Since 2014, the newly recruited students pursuing the professional master's degree of clinical medicine (professional masters) should complete the postgraduate study and participate in the standardized training of residents (residents' training) as a trainee, which is the so-called "two-track integration" model. By implementing this model, both an opportunity and a challenge are created for professional masters (Wei et al., 2019). For the students, they need to complete clinical practice training in 33 months in the hospital, as well as a range of courses and the corresponding scientific research tasks of the school. Professional masters will be subject to considerable difficulties on learning professional knowledge due to limited time and energy. Moreover, numerous aspects require improvement for "two-track integration" model. In the present study, some of the problems currently encountered are analyzed in depth, and some solutions are generated to provide some suggestions and references for the professional masters.

\section{Problems and Phenomena in the "Two-Track Integration" Mode}

\subsection{Little Emphasis on Rotating Departments}

Due to little emphasis on rotating departments, the professional masters gain insufficient attention to other departments and lack a sense of belonging to the mentioned departments, thereby causing a vague or even incomprehensible cognition of correlative professional knowledge for them. Worsely, the teachers in the department are busy, and students are given less time for guidance and training, so a deficiency is caused in the relevant knowledge for professional masters (Song, Yang, Liu, Hong, \& Li, 2019). The mentioned phenomenon, as opposed to the concept of "residents' training", adversely affects the growth of students, while violating the country's original intention of training comprehensive medical personnel.

\subsection{Little Attention to the Enhancement of Scientific Research Capabilities}

During the day, professional masters work in the hospital with heavy clinical work; at night and weekends, they attend classes. Thus, they all have a full schedule, forcing them to conduct scientific research only in their spare time and rest time. Moreover, since the coordination in time is lacked, professional masters tend to easily ignore scientific research. After receiving three years of training, they have relatively lower scientific research ability than academic masters, which can't satisfy the national standards for training senior talents.

\subsection{Poor Paper Writing Ability and Low Paper Quality}

A large number of professional masters are not proficient in analyzing, studying, 
absorbing and digesting the literature without reading considerable literature, therefore, some professional masters gain poor paper writing ability and achieve low-quality published papers (Zhao, Zhou, Zhu, Jia, \& Wu, 2020). Such a situation impedes the scientific research ability of the professional masters from future developing, and can't guarantee their long-term development. Graduate students without certain scientific research capabilities are not consistent with the original intention of the country, universities and hospitals to nurture comprehensive clinical talents.

\subsection{It Is Difficult to Get Close Contact between Some Professional Masters and Their Tutors}

The tutors usually have multiple jobs and are busy with daily work, because of which, a tutor could be hard to supervise a professional master on both study life and scientific research. For this reason, some students can't study with their tutors for a full time, but only choose to stay in the training base arranged by the university. Due to the lack of supervision, a significant number of students feel that they have the wrong learning orientation. Even worse, for the lack of self-discipline, they think that they have no control and begin to indulge themselves. Students who can be taught by tutors are lucky, whereas there are also not a few students not closely connected with tutors for various reasons (Mo, Tao, Tang, Zhou, Wang, \& Huang, 2016). A professional master without the correct world outlook, outlook on life, and value led by a mentor is likely to go astray in clinical work and even put himself in jail.

\subsection{Low Salary of the Professional Master with the Identical Work Intensity}

During the residency training for professional masters, the study period is long, the work is busy, and the salary is relatively low high. A small salary allowance issued by the country each month acts as the biggest source of income for them (He, Duan, Wu, Zhang, Wu, \& Zou, 2019). On the whole, professional masters are aged from 25 to 30 years, i.e., the age group to share family responsibilities. Such a gap in treatment limits masters to devote themselves to scientific research and work. Thus, professional masters are not superior over other workers of the same age group and under the same work intensity. The low pay, coupled with long working hours and high psychological pressure, make the professional masters feel exhausted in the working environment.

Targeted on the problems listed above, we provide specific solutions, which came to mind during daily education on medical students, including those professional masters.

\section{Solutions}

\subsection{Recognize Your Own Learning Philosophy and Learning Goals}

Professional masters in the new era should develop the habit and philosophy of 
constantly rethinking self-behavior in work and study profoundly. They must always remind themselves, demand themselves with high standards, work hard to act as a comprehensive clinical professional, and prepare for meeting future job needs and work progress. As upheld from the "Opinions on Expediting the Reform and Development of Postgraduate Education in the New Era" jointly issued by the Ministry of Education, the National Development and Reform Commission, and the Ministry of Finance clearly mentions, "We should be guided The Thought on Socialism with Chinese Characteristics for a New Era proposed by the president Xi Jinping, fully implement the educational policy of the CPC (Communist Party of China), and firmly comply with the line of connotative development". Focusing on fostering people, serving demands, improving quality and pursuing excellence, it is necessary to face the forefront of world technological competition, the main battlefield of economic and social development, the emerging needs of the people and the grand strategy of national governance, and aim at the frontier and key of science and technology field to press ahead the adjustment of disciplines, elevate the level of tutors and the talent training system. Furthermore, it is required to promote postgraduate training units to develop their own characteristics and standards, and expedite the establishment of a strong postgraduate education country to provide strong talents and intellectuals support for upholding and developing socialism with Chinese characteristics and fulfilling the China Dream of the great rejuvenation of the Chinese nation. The present study highlights the country's stress on postgraduate education, while proposing the expectations and requirements to nurture well-rounded talents. Specific to political thought, the professional masters should implement their beliefs, abide by the leadership of the Communist Party of China, rigorously require and exercise themselves, and contribute to the country's exploration in the frontier fields of science and technology and talent reserves. The mentioned refer to the qualities and capabilities that contemporary professional masters should exhibit. In daily life study, whether studying in the major department or not, they should go all out and take it seriously. It aims to cherish the training opportunities, as well as better develop themselves in the future. It should be considered that knowledge between different disciplines is interconnected. Furthermore, only with a proficiency in multi-disciplinary knowledge can the professional masters be calmer when coping with complex and systemic diseases in the future.

\subsection{Stress Scientific Research Education and Strengthen the Cultivation of Scientific Research Quality}

In the new era, the social economy is developing rapidly, and the people hold higher requirements for medical technology. The steady development of national medical and health undertakings refers to the main link in China's current national governance environment, and the development of frontiers and vital areas of medical technology is recognized as one of the relevant cores. The core competitiveness of the country comes from scientific research and the people's live in 
peace is also inseparable from it (Du, Wang, \& Cao, 2020). Graduate education is essentially cultivating, innovative, professional, advanced and free (Yao, 2018). For a professional master, it is not easy to complete 33-months clinical practice skills training, as well as to consider both learning and scientific research. If they use this as a reason, neglecting scientific research and learning will practically make the education of professional masters easily violate the essence of graduate education. The teaching unit is highly required to make students focus on cultivating scientific research quality from the beginning of admission, facilitate the implementation of the concept of scientific research education, make students pay attention to scientific research, as well as improve scientific research ability (Zou, Zhang, Wu, \& An, 2020). Moreover, teaching units should stress the individualized development of professional masters, and may give them a certain amount of free time to coordinate the conflict between work and research. Studies on scientific research can combine the experiences and experience of the tutor, or it can allow students with ideas to develop a learning method independently. As the tutor and classmates, through combining scientific research practice and clinical experience, they can realize what they want, do and gains. Lastly, they can summarize a training path and teaching plan that are most suitable for themselves.

\subsection{Enhance Literature Reading Ability and Essay Writing Ability}

As one of the vital talents cultivated in national education, professional masters are required to have certain knowledge reserves and scientific research capabilities. First, though the tutor is an instructor of professional masters' study, after the instruction, they should still practice to effectively combine scientific assumptions and verification, and then it is possible to be exposed to deeper research for them. Subsequently, if they can get more opportunities of engaging in the tutor's project and academic communications, the more the number of topics involved, and the higher the level of academic conferences they participate in, the more the opportunities they will get to publish high-quality papers as the first author (Zeng, Xia, Yi, \& Yang, 2020). Literature reading refers to an essential part of improving research and learning. Actively participating in the research of the tutor's subject can exercise one's scientific research ability, as well as exercise one's patience and will. In high-level academic conferences, they can get gain insights into new fields and new developments of professional knowledge faster and more accurately, thereby helping broaden their own horizons and exercise their thinking skills, as well as helping them find novel clues for their own research earlier to present better ideas for their own follow-up research and enhance their professional knowledge and thinking. The mentioned points are necessary measures for professional masters to improve the ability of writing papers and the quality of papers. By receiving directional literature reading guidance and purposeful meeting learning to combine the direction of the tutor's subject with practice, and then by proposing ideas, the professional masters can faster and better improve their paper writing ability. 


\subsection{Build a Communication Bridge between Teachers and Students, and Set up a Professional Tutor Team}

Tutors are the first person responsible for postgraduate training. Accordingly, the close contact between students and tutors should be maintained. The use of mobile communication software commonly used today can reduce communication costs and increase communication efficiency. Research and investigation found that "WeChat" as the most frequently used information transmission method is very popular among the public (Guan, Lin, Hu, Liu, Jin, \& Lu, 2017). It is capable of achieving the communication in language text messages, videos, pictures and texts. Accordingly, students can maintain considerable communication with their tutors, transfer learning resources and quickly communicate information. Moreover, it can help tutors understand students' daily study and work life via WeChat, and can also provide some suggestions of clinical practice and scientific research to help students grow better. However, it is noteworthy that in WeChat communication, teacher-student communication can easily become a single message instillation that the message transmission of tutors will rapidly turn into command information, and students lack feedback. Unilateral instructional information makes it impossible for both teachers and students to communicate effectively, and students are afraid and feel inconvenient to ask. To be specific, when the tutor and the professional master are not in the identical teaching unit, software information communication alone cannot provide effective guidance. When subject to difficulties, students usually lack certain professional knowledge about the problem itself, and do not know how to describe the problem, so they cannot express effective inquiry via information. This largely limits the growth of students. Thus, if conditions permit, students not studying with their tutors can be provided with 3 - 5 professional tutors in a team, and tutor assistants or teams can be arranged to carry forward the growth and study of students, which can, to a certain extent, remedy the defects of students who cannot get timely guidance in study and work due to insufficient communication between the tutor and the student (Yu, Guo, Dai, \& Pei, 2018).

\subsection{Appropriately Increase the Salary of Masters}

With tight curriculum time, busy clinical work and heavy scientific research tasks, professional masters exhibit slight age advantage, little income and higher pressure, as opposed to people of the same age, and it is more likely to produce anxiety for them. Anxiety affects the life and study of professional masters and will cause some bad feelings (e.g., laziness and slack), which is significantly adverse to the growth and development of them. By appropriately promoting the salaries of professional masters, or establishing a relevant reward system according to the situation, the burden on students and eliminate anxiety can, to a certain extent, be reduced.

\section{Practical Implications}

During daily clinical work and training in those professional masters, we have 
put the above solutions into practice. At beginning, we simply increased the payment to the professional master's work under hospital's financial policies, however, in name of encouraging their scientific research. Obviously the students kept much more optimistic attitude to both colleagues and their scientific research. But this doesn't last long. In this case, increasing the salary could be good to start to invert students' attitude to be more positive. To maintain their positive attitude, we initiated cross talks on their learning philosophy, and make it clear for them to their life careers. Moreover, we seized every opportunity to spare enough time for the professional maters' time, to encourage their performance on literature reading, summarizing, discussion and so on. To make a better communications to the students, we gave up those tedious lecturing, instead, we usually started the communication with their personal interests, for example, their favorite sport teams, movies and books. Such a topic usually to achieve a common interest, then step by step we led the talk into medical topics, to cells and to proteins, etc.

After years of implement of the activity listed above, it is clearly to observe that most of the professional maters exhibited stronger self-confidence in selflearning, strong ability in research design, data analyzing, scientific paper writing, and a higher frequency of them to call their tutors for making appoints for discussion on clinical work and laboratory research. Besides, their medical record writing ability also increased significantly, which is beyond our expectation.

\section{Conclusion}

How to nurture comprehensive clinical talents for the country in the "two-track integration" mode is recognized as a question we have been discussing. Through continuous exploration of the professional master education, more problems can be discovered, so we can continue to improve and innovate, and create a path more suitable for the cultivation of professional masters of clinical medicine in China. The present study proposes some opinions and ideas by cultivating professional masters, as an attempt to further formulate and improve the implementation of the policies of graduate education to develop professional masters comprehensively, as well as to gain insights and thinking into the future graduate education.

\section{Founding}

Guangxi degree and postgraduate education reform project in 2019: Research on the standardization of talent cultivation for clinical medical degree postgraduates based on the model of two-track (No: JGY2019161).

Guangxi Medical High-level Leading Talents Training “139” Project, Special Funding for Guangxi Special Experts.

Exploration of the Application of Case-based learning Combined with Small Private Online Course and Massive Open Online Course Teaching Model in Ga- 
strointestinal Surgery (No: 2020JGA277).

Guangxi Natural Science Foundation (No: 2020GXNSFAA259050).

Youjiang Medical University for Nationalities Research Project (No: yy2019bsky001).

Undergraduate Teaching Reform Project of Guangxi Higher Education (No: 2019JGA266).

\section{Conflicts of Interest}

The authors declare no conflicts of interest regarding the publication of this paper.

\section{References}

Du, P., Wang, Z. D., \& Cao, Q. (2020). Several Trends and Enlightenments of the Development of World Science. Bulletin of the Chinese Academy of Sciences, 35, 555-563.

Guan, R. Z., Lin, R. J., Hu, S. J., Liu, X. M., Jin, R., \& Lu, L. (2017). Analysis of the Application of WeChat in the Cultivation of Clinical Medicine Masters. Continuing Medical Education in China, 9, 30-32.

He, Y. F., Duan, C. Z., Wu, J., Zhang, S. Q., Wu, J., \& Zou, W. J. (2019). Satisfaction Status and Influencing Factors of Postgraduate Cultivation with Professional Master Degree of Clinical Medicine in a University in Chongqing. Medicine and Society, 32, 126-130.

Mo, X. Q., Tao, L. H., Tang, Q. L., Zhou, Z. W., Wang, L. Y., \& Huang, L. (2016). Study on the Cultivation of Scientific Research Ability of Clinical Medical Degree under the “Double Track Integration” Model. China Medical Education Technology, 30, 13-14.

Song, T. W., Yang, H., Liu, X. D., Hong, C. Y., \& Li, X. G. (2019). Research on the Improvement of Hospital Department Rotation Plan for Standardized Training of General Practitioners. Chinese General Practice, 22, 1209-1212.

Wei, J. H., Zhuo, C. Y., Bao, C. C., Tang, Q. L., Feng, S., Huang, L. F., Xu, Y., \& Wang, X. L. (2019). Research on the Standardization of Talent Cultivation for Clinical Medical Degree Postgraduates Based on the Model of Two-Track Integration. Creative Education, 10, 3293-3298. https://doi.org/10.4236/ce.2019.1013252

Yao, J. Y. (2018). Analysis on the Essence of Graduate Education from Multiple Perspectives. Higher Education Research of Heilongjiang, 2, 13-16.

Yu, S. M., Guo, D. D., Dai, L. J., \& Pei, C. P. (2018). Exploration on the Application of the Teaching Model of the Cooperative Group Teaching of Postgraduate Tutors of Integrated Traditional Chinese and Western Medicine. Education \& Teaching Forum Periodicals Agency, 10, 196-197.

Zeng, W., Xia, B. H., Yi, Z. H., \& Yang, J. L. (2020). The Influence of Scientific Research Training Mode on the Output of Clinical Medicine Professional Masters. Medical Education Research and Practice, 28, 604-607+632.

Zhao, H. Y., Zhou, Y., Zhu, W., Jia, B. F., \& Wu, G. (2020). Exploration of the Training Model for Master Degree Students of Clinical Medicine under the Background of Medical Education Collaboration.Basic Medical Education, 22, 604-607.

Zou, W. J., Zhang, S. Q. Wu, J., \& An, Z. Y. (2020). Satisfaction Status and Influencing Factors of Research Ability Cultivation of Clinical Medicine Professional Masters in 8 Medical Universities in the "Two-Track Integration" Model. Medicine and Society, 33, 125-129. 